\title{
Analisis Video Comments to Likes Ratio Tiktok Pada 5 Merek Smartphone Terlaris di Dunia
}

\author{
Gusti Agung Dikse Semadi
}

gustiagungdikse01@gmail.com

\begin{abstract}
TikTok is a social media application launched by a Chinese company. TikTok allows users to create 15 -second videos accompanied by music, filters, and several other creative features. In Indonesia, there are 30.7 million active users, making Indonesia the country with the largest TikTok users in the world. The large number of active TikTok users in Indonesia can certainly provide an opportunity for brands to make the TikTok platform a social media marketing platform. There are 5 best selling smartphone brands in the world that use TikTok as a marketing platform, namely: Oppo Indonesia, Samsung Indonesia, Vivo Indonesia, Xiaomi Indonesia, and Realme Indonesia. The purpose of this study is to calculate the credibility of the TikTok account performance of the Top 5 Best Selling Smartphone Brands in the World. The method used for this research is quantitative exploratory method. The results of this study indicate that the smartphone vendor Oppo Indonesia is ranked first and has good account performance credibility.
\end{abstract}

\begin{abstract}
ABSTRAK
TikTok merupakan aplikasi sosial media yang diluncurkan oleh perusahaan asal Tiongkok. TikTok memungkinkan penggunanya membuat video berdurasi 15 detik yang disertai dengan musik, filter, dan beberapa fitur kreatif lainnya. Di Indonesia terdapat 30,7 juta pengguna yang aktif sehingga menjadikan Indonesia sebagai negara dengan pengguna TikTok terbesar di dunia. Maraknya jumlah pengguna TikTok yang aktif di Indonesia tentu dapat memberikan peluang bagi brand untuk menjadikan platform TikTok sebagai platform social media marketing. Adapun 5 merek smartphone terlaris di Dunia yang memanfaatkan TikTok sebagai platform marketing, yaitu : Oppo Indonesia, Samsung Indonesia, Vivo Indonesia, Xiaomi Indonesia, dan Realme Indonesia. Tujuan dari penelitian ini yaitu untuk menghitung kredibilitas dari performa akun TikTok Top 5 Merek Smartphone Terlaris di Dunia. Metode yang digunakan untuk penelitian ini yaitu metode eksploratif kuantitatif. Hasil dari penelitian ini menunjukan bahwa vendor smartphone Oppo Indonesia mendapatkan peringkat pertama dan memiliki kredibilitas performa akun yang baik.
\end{abstract}

Keyword : Credibility Account TikTok ; Social Media Marketing ; Social Media TikTok ;Video Comments to Video Like Ratio ; Merek Smartphone Indonesia. 


\section{PENDAHULUAN}

Teknologi informasi dan komunikasi yang telah berkembang pesat mampu menghantarkan manusia untuk menciptakan bentuk baru dalam cara berkomunikasi serta berinteraksi melalui media sosial. Media sosial memberikan pengaruh yang cukup besar, saat ini media sosial dijadikan sarana berkomunikasi dalam setiap aktifitas keseharian bersosial di masyarakat. Komunikasi tidak hanya dapat dilakukan secara fisik, tetapi juga dapat dilakukan dengan menggunakan berbagai aplikasi media sosial di dunia maya. Keunggulan layanan aplikasi sosial media adalah memberikan ruang komunikasi dua arah antara konsumen - perusahaan dan konsumen - konsumen.

Dengan pesatnya perkembangan teknologi media sosial, telah memberikan dampak terhadap situs - situs komunikasi, dari yang awalnya hanya sekedar email dan chatting, saat ini sudah banyak jejaring media sosial yang bisa digunakan sebagai alat komunikasi. Contoh aplikasi sosial media yang memiliki banyak pengguna saat ini yaitu TikTok. TikTok merupakan aplikasi yang diluncurkan oleh perusahaan asal Tiongkok. Tiktok memungkinkan penggunanya membuat video berdurasi 15 detik yang disertai dengan musik, filter, dan beberapa fitur kreatif lainnya (Adawiyah 2020).

Kehadiran media sosial TikTok dapat membangun sebuah brand, TikTok juga dapat membangun personal branding pemiliknya (Ishihara and Oktavianti 2021). Di Indonesia, terdapat 30,7 juta pengguna TikTok yang aktif sehingga menjadikan Indonesia sebagai negara dengan pengguna TikTok terbesar di dunia. Maraknya jumlah pengguna TikTok aktif di Indonesia tentu dapat memberikan peluang bagi brand untuk menjadikan platform ini sebagai platform social media marketing. Cukup banyak akun perushaan - perusahaan terkenal yang ada pada tiktok, contohnya seperti merk smartphone di Indonesia. Adapun 5 Merek Smartphone Terlaris di Dunia, diantaranya yaitu : Oppo Indonesia, Samsung, Vivo Indonesia, Xiaomi Indonesia, Iphone Storess ("5 Merek Smartphone Terlaris di Dunia” n.d.).

Penelitian ini menggunakan metode eksploratif kuantitatif, dan akan menghitung menggunakan rasio - rasio yang ada pada TikTok. Pada penelitian (Permana and Meinarni 2021) menjelaskan bahwa terdapat 17 rasio yang ada pada sosial media TikTok dan relevan digunakan sebagai media ukur kredibilitas akun yang ada. Penelitian ini hanya berfokus untuk menghitung kredibilitas Video Comments to Likes Ratio pada "5 Merek Smartphone Terlaris di Dunia"(Gilar Ramdhani, n.d.). Tujuan dari penelitian ini adalah mengetahui kredibilitas performa dari akun TikTok 5 Merek Smartphone Terlaris di Dunia menggunakan Video Comments to Likes Ratio.

\section{TINJAUAN PUSTAKA}

Perkembangan bidang teknologi saat ini terjadi begitu pesat. Melalui perkembangan yang terjadi dari waktu ke waktu menimbulkan maraknya aplikasi - aplikasi serta platform media sosial yang bermunculan. Aplikasi yang sangat diminati oleh masyarakat saat ini diantaranya adalah TikTok, Instagram, Twitter, WhatsApp dan yang lain sebagainya. Seiring berjalannya waktu, aplikasi sosial media tersebut dapat menjadi candu bagi kalangan masyarakat. Tidak hanya kalangan remaja yang menggunakan aplikasi sosial media, orang tua bahkan anak-anak juga aktif menggunakan aplikasi sosial media tersebut. 
Tiktok merupakan bagian dari new media yang memiliki perkembangan terpesat dibandingkan dengan kategori new media yang lainnya seperti facebook, Instagram, YouTube, dan Twitter (P3M STMIK Widya Cipta Dharma, n.d.). Dari sekian banyak aplikasi sosial media, TikTok menjadi aplikasi yang memiliki pengguna aktif terbanyak. TikTok merupakan jejaring sosial media dalam bentuk video yang umumnya berdurasi 15 detik. Pada aplikasi TikTok pengguna dapat membuat video dengan filter-filter yang spesial serta menggunakan lagu yang sedang trending. Selain itu, pengguna dapat membagikan video yang dibuat ke aplikasi lain seperti Instagram ataupun Twitter (PRIANBODO 2018).

Salah satu ciri khas sosial media TikTok adalah halaman utamanya yang Bernama For Your Page atau FYP. Pengguna yang cukup sering ditayangkan dalam FYP dapat menjadi populer dan memiliki banyak pengikut, yang biasa disebut sebagai seleb TikTok (Putri and Azeharie 2021).

Di Indonesia, fenomena anak muda dalam menggunakan TikTok menunjukan antusiasme yang sangat massif. Meraka berlomba membangun identitas demi mendapatkan citra yang diinginkan, seperti dipuji dan dikenal oleh banyak orang (Wijaya and Mashud 2020). Aplikasi TikTok semakin populer sejak diluncurkan tahun 2016. Bahkan TikTok telah mencetak berbagai macam prestasi, salah satunya yaitu menyalip pendapatan iklan digital di negaranya yaitu pendapat Google China, Patio (Batam 2020).

Aplikasi TikTok tidak hanya digunakan untuk membuat konten video dengan tujuan menghibur pengguna lainnya. Aplikasi TikTok juga dapat dijadikan peluang bagi brand atau perusahaan sebagai platform social media marketing. Penelitian (Purnamasari and Tutiasri 2021) menyatakan bahwa TikTok berpengaruh positif dan signifikan terhadap minat beli atau berbelanja secara online. Sehingga dengan ini, TikTok mampu memberikan peluang yang sangat tinggi bagi perusahaan-perusahaan dalam melakukan digital marketing.

TikTok dirasakan memiliki kekuatan ataupun pengaruh dalam industri, sehingga menimbulkan kualitas akun yang menentukan strata maupun kredibilitas pemilik akun. Kredibilitas akun TikTok merupakan suatu hal yang cukup penting untuk berbagai kepentingan. Kredibilitas sebuah akun TikTok dapat diukur dari tingkat performa yang dihasilkan secara matematis. Dalam mengukur performa diperlukan skala pengukuran yang tertuang ke dalam rasio.

\section{METODE PENELITIAN}

Penelitian ini menggunakan metode eksploratif kuantitatif untuk mengetahui kredibilitas dari performa akun TikTok 5 Merk Smartphone Terlaris di Dunia Q1 2021. Metode eksploratif merupakan penelitian yang memiliki tujuan untuk melakukan eksplorasi atau memperdalam pengetahuan ataupun ide - ide baru mengenai suatu hal yang baru, guna merumuskan permasalahan secara terperinci (Maryam, Isrok'atun, and Aeni 2016).

Tujuan dari penelitian ini yaitu mengetahui nilai kredibillitas dari performa akun TikTok 5 Merk Smartphone Terlaris di Dunia Q1 2021. Ada beberapa langkah yang harus dilakukan dalam penelitian ini, sehingga mampu menemukan peringkat pertama akun TikTok Merk 
Smartphone Terlaris di Dunia yang memiliki performa terbaik. Langkah-langkah yang dilakukan pada penelitian ini, diantaranya yaitu:

\section{Melakukan Eksplorasi Pada Website Untuk Menentukan Objek yang Akan Dianalisa.}

Eksplorasi ini dilakukan pada beberapa halaman website yang menyediakan informasi mengenai objek yang akan di teliti. Setelah ekslorasi selesai dilakukan, sehingga ditemukan nama-nama Merk Smartphone Terlaris di Dunia yang akan dijadikan objek analisa. Setelah melakukan eksplorasi pada halaman website, maka langkah selanjutnya yaitu mencari nama akun TikTok dari masing-masing vendor smartphone. Pastikan semua merk memiliki akun pada aplikasi sosial media TikTok.

\section{Menghitung Nilai Rata-Rata Variable Dari 5 Merk Smartphone Terlaris di Dunia.} Pada langkah ini, peneliti menghitung nilai variable video comments dan variable video views. Variabel merupakan sesuatu yang memiliki nilai bervariasi dimana nilai tersebut dapat dijadikan sebagai dasar untuk empat data yang berbeda seperti rasio, skala, ordinal, nominal dan internal (Rankuti 2015). Untuk menghitung nilai rata-rata dari Video Comments to Likes Ratio Tiktok yaitu dengan cara mengambil minimal 10 postingan kemudian di hitung sehingga menemukan nilai rata-rata dari masing-masing variabel.

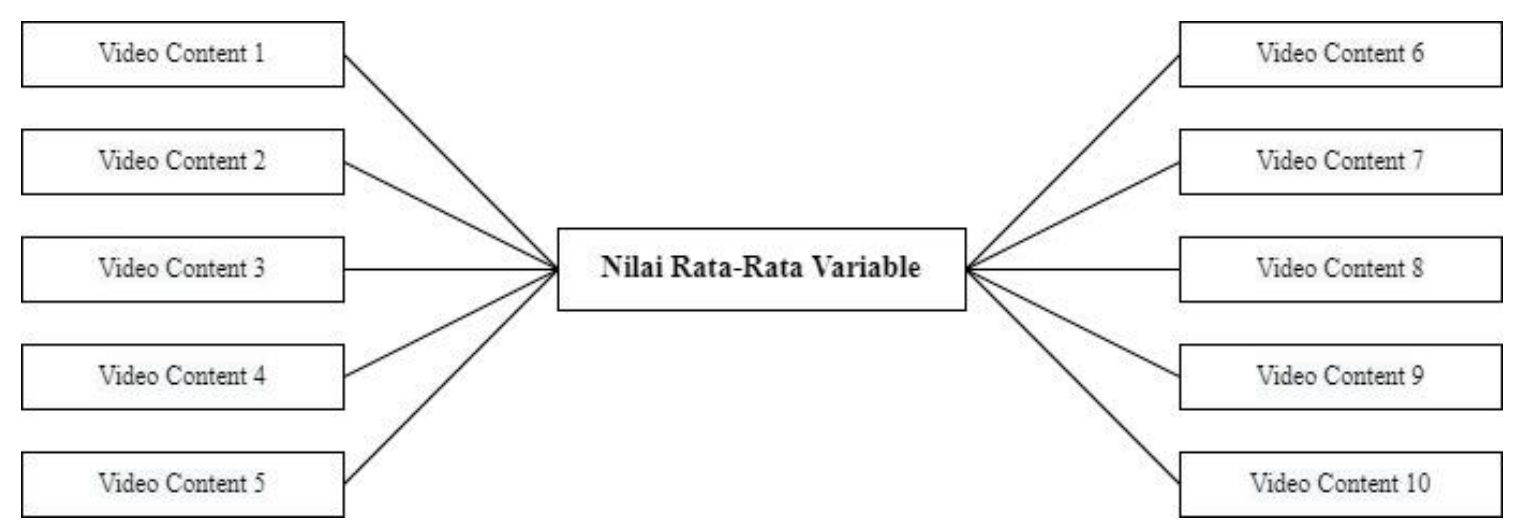

Gambar 1. Analisa Nilai Rata-Rata Variabel.

\section{Menghitung Nilai Kredibilitas Rasio}

Untuk menghitung nilai kredibilitas dari video comments to video views ratio, peneliti menggunakan cara membagi nilai variabel pertama dengan nilai variabel kedua. Jika video comments memiliki nilai 100 dan Video Likes memiliki nilai 300, maka cara menghitungnya yaitu $100: 300=0,3$. Dengan begitu nilai dari Video Comments to Likes Ratio Tiktok adalah 0,3.

\section{Menentukan Peringkat Pada Akun TikTok}

Pada langkah terakhir yang dilakukan pada penelitian ini yaitu menentukan peringkat pada masing-masing rasio yang ada. Pada penentuan peringkat perlu melihat karakteristik dari rasio yang di teliti. Jika karakteristik rasio merupakan rendah, maka objek yang memiliki nilai terendah akan mendapatkan angka 5 dan objek yang memiliki 
nilai tertinggi akan mendapatkan angka 1. Namun jika rasio memiliki karakteritik tinggi maka objek yang mendapatkan nilai tinggi akan mendapatkan angka 5 dan objek yang mendapatkan nilai terendah akan mendapatkan angka 1. Setelah mendapatkan hasil kredibilitas ratio maka dapat disimpulkan objek yang mana mendapatkan peringkat 1 sampai dengan peringkat 5 .

\section{HASIL DAN PEMBAHASAN}

Akun TikTok dari Top 5 Merek Smartphone Terlaris di Dunia Q1-2021, diantaranya :

\section{Oppo Indonesia}

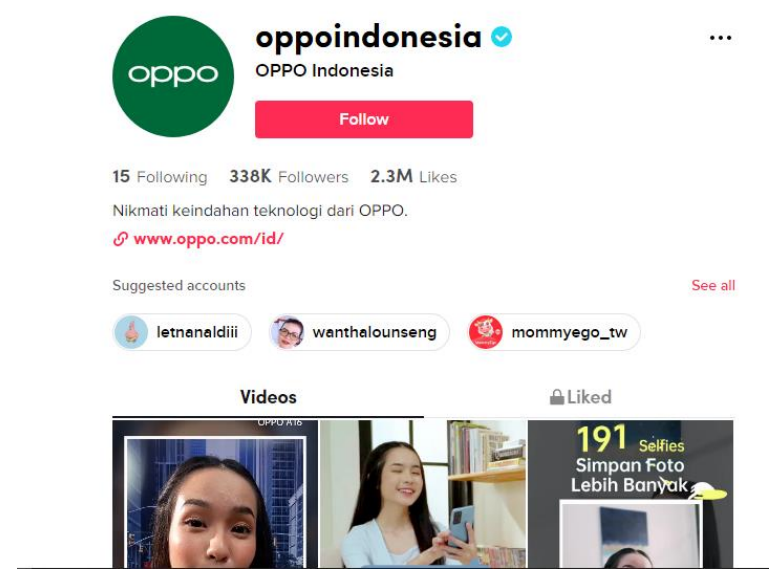

Gambar 1. Akun TikTok Oppo Indonesia

Sumber : https://www.tiktok.com/@oppoindonesia? (akses pada 21-10-2021)

\section{Samsung}

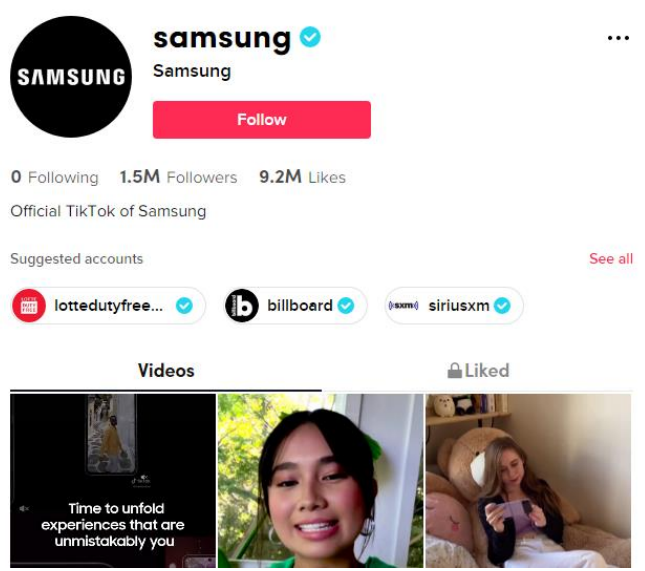

Gambar 2. Akun TikTok Samsung Indonesia

Sumber : https://www.tiktok.com/@samsung? (akses pada 21-10-2021) 


\section{Vivo Indonesia}

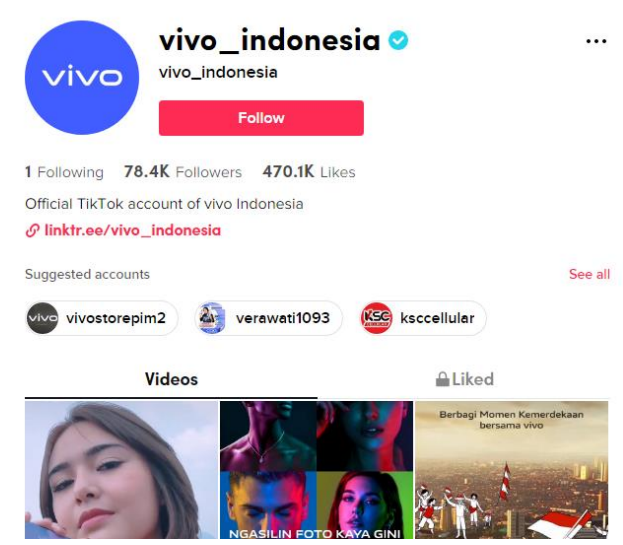

Gambar 3. Akun TikTok Vivo Indonesia

Sumber : https://www.tiktok.com/@vivo_indonesia? (akses pada 21-10-2021)

\section{Xiaomi Offficial}

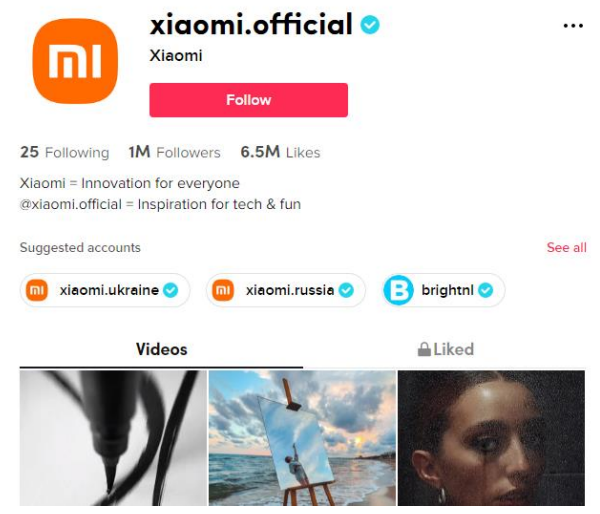

Gambar 4. Akun Tiktok Xiaomi Indonesia

Sumber : https://www.tiktok.com/@xiaomi.official? (akses pada 21-10-2021)

\section{Iphone Storess}

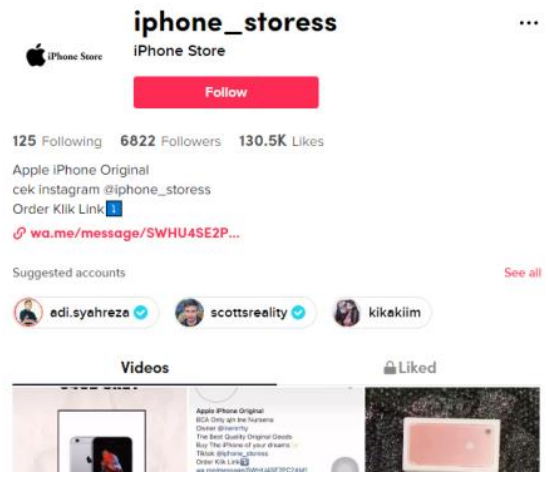

Gambar 5. Akun TikTok Realme Indonesia

Sumber : https://www.tiktok.com/@iphone_storess? (akses pada 21-10-2021) 
Dari kelima akun TikTok 5 Merek Smartphone Terlaris di Dunia, peneliti menemukan nilai dari masing-masing variabel yang ada untuk menghitung rasio Video Comments to Video likes dari setiap akun. Pada akun TikTok terdapat 7 variabel, diantaranya yaitu :

1. Likes

2. Followers

3. Following

4. Video Likes

5. Video Comments

6. Video Share

7. Video Views

Dari ketujuh variabel tersebut peneliti hanya fokus untuk menemukan hasil dari 2 variabel, yaitu :

\section{Video Comments \\ 2. Video Likes}

Dari kedua variabel tersebut kemudian dianalisa sehingga menemukan nilai rata-rata dari variabel video comments dan variabel video likes. Untuk menghitung nilai rata-rata dari variabel video comments dan variabel video likes yaitu dengan cara mengambil minimal 10 postingan kemudian di hitung sehingga menemukan nilai rata-rata dari masing-masing variabel. Berikut merupakan tabel nilai rata-rata dari masing-masing merek smartphone di Indonesia, yaitu :

Tabel 1. Analisa Nilai Rata-Rata Nilai Variabel Video Comments dan Video Likes Akun TikTok Oppo Indonesia

\begin{tabular}{|c|c|c|}
\hline No & $\begin{array}{c}\text { Video } \\
\text { Likes }\end{array}$ & Video Comment \\
\hline 1 & 136 & 9 \\
\hline 2 & 22.500 & 154 \\
\hline 3 & 627 & 21 \\
\hline 4 & 932 & 14 \\
\hline 5 & 184 & 2 \\
\hline 6 & 586 & 14 \\
\hline 7 & 330 & 6 \\
\hline 8 & 469 & 13 \\
\hline 9 & 24.500 & 29 \\
\hline 10 & 22.400 & 27 \\
\hline Total & 7.266 & 29 \\
\hline
\end{tabular}


Tabel 2. Analisa Nilai Rata-Rata Nilai Variabel Video Comments dan Video Likes Akun TikTok Samsung

\begin{tabular}{|c|c|c|}
\hline No & $\begin{array}{l}\text { Video } \\
\text { Likes }\end{array}$ & Video Comment \\
\hline 1 & 1.721 & 215 \\
\hline 2 & 3.657 & 326 \\
\hline 3 & 6.379 & 313 \\
\hline 4 & 2.132 & 432 \\
\hline 5 & 1.210 & 44 \\
\hline 6 & 3.163 & 196 \\
\hline 7 & 1.266 & 87 \\
\hline 8 & 1.225 & 53 \\
\hline 9 & 3.771 & 336 \\
\hline 10 & 4.690 & 111 \\
\hline Total & 2.921 & 211 \\
\hline
\end{tabular}

Tabel 3. Analisa Nilai Rata-Rata Nilai Variabel Video Comments dan Video Likes Akun TikTok Vivo Indonesia

\begin{tabular}{|c|c|c|}
\hline No & $\begin{array}{c}\text { Video } \\
\text { Likes }\end{array}$ & Video Comment \\
\hline 1 & 711 & 169 \\
\hline 2 & 333 & 11 \\
\hline 3 & 181 & 6 \\
\hline 4 & 178 & 1 \\
\hline 5 & 290 & 12 \\
\hline 6 & 46.500 & 81 \\
\hline 7 & 30.700 & 49 \\
\hline 8 & 18.500 & 11 \\
\hline 9 & 151 & 18 \\
\hline 10 & 150 & 2 \\
\hline Total & 9.769 & 36 \\
\hline \multicolumn{3}{|c|}{ Sumber $:$ Pengolah Data Excel }
\end{tabular}


Tabel 4. Analisa Nilai Rata-Rata Nilai Variabel Video Comments dan Video Likes Akun TikTok Xiaomi Official

\begin{tabular}{|c|c|c|}
\hline No & $\begin{array}{c}\text { Video } \\
\text { Likes }\end{array}$ & Video Comment \\
\hline 1 & 52.700 & 1.053 \\
\hline 2 & 118.800 & 2.225 \\
\hline 3 & 79.500 & 1.175 \\
\hline 4 & 1.340 & 22 \\
\hline 5 & 446 & 10 \\
\hline 6 & 110 & 8 \\
\hline 7 & 5.676 & 19 \\
\hline 8 & 4.733 & 129 \\
\hline 9 & 4.584 & 35 \\
\hline 10 & 872 & 11 \\
\hline Total & 26.876 & 469 \\
\hline \multicolumn{3}{|c|}{ Sumber $:$ Pengolah Data Excel }
\end{tabular}

Tabel 5. Analisa Rata-Rata Nilai Variabel Video Comments dan Video Likes Akun TikTok Iphone Storess

\begin{tabular}{|c|c|c|}
\hline No & $\begin{array}{c}\text { Video } \\
\text { Likes }\end{array}$ & Video Comment \\
\hline 1 & 9.501 & 438 \\
\hline 2 & 75.100 & 1.021 \\
\hline 3 & 31.400 & 1.359 \\
\hline 4 & 21 & 0 \\
\hline 5 & 48 & 2 \\
\hline 6 & 90 & 13 \\
\hline 7 & 51 & 3 \\
\hline 8 & 2.456 & 454 \\
\hline 9 & 316 & 17 \\
\hline 10 & 286 & 17 \\
\hline Total & 11.927 & 332 \\
\hline \multicolumn{3}{|c|}{ Sumber : Pengolah Data Excel } \\
\hline
\end{tabular}

Setelah menghitung nilai rata-rata tersebut, maka akan menemukan hasil akhir nilai rata-rata dari variabel video comments dan video likes nya.

Tabel 6. Nilai Variabel Pada Akun TikTok Top 5 Merek Smartphone Terlaris di Dunia

\begin{tabular}{|l|c|c|c|c|c|}
\hline \multicolumn{1}{|c|}{ Variable } & Vivo_Indonesia & xiaomi.official & SAMSUNG & iphone_storess & OPPO \\
\hline Video Likes & 9.769 & 26876 & 2921 & 11927 & 7266 \\
\hline $\begin{array}{l}\text { Video } \\
\text { Comments }\end{array}$ & 36 & 469 & 211 & 332 & 29 \\
\hline
\end{tabular}


Pada akun TikTok terdapat 17 rasio yang relevan digunakan untuk mengukur kredibilitas pada masing-masing akun. Namun pada penelitian kali ini hanya berfokus untuk menghitung Video Comments to Video Likes Ratio. Untuk menghitung kredibilitas dari masing-masing akun TikTok setiap merk smartphone, peneliti menghitung dengan cara : variabel 1 akan dibagi dengan variabel 2 , sehingga ditemukan hasil analisisa dari rasio tersebut.

Tabel 7. Hasil Perhitungan Rasio Akun TikTok

\begin{tabular}{|c|l|c|c|c|c|c|c|}
\hline No & RATIO & $\begin{array}{c}\text { Vivo_ } \\
\text { Indonesia }\end{array}$ & $\begin{array}{c}\text { xiaomi. } \\
\text { official }\end{array}$ & SAMSUNG & $\begin{array}{c}\text { iphone_ } \\
\text { storess }\end{array}$ & OPPO & Karakteristik \\
\hline 1 & $\begin{array}{l}\text { Video } \\
\text { Comments } \\
\text { to Video } \\
\text { Likes Ratio }\end{array}$ & 0,00368513 & 0,01745051 & 0,07223554 & 0,02783600 & 0,00399119 & Tinggi \\
\hline
\end{tabular}

Sumber : Pengolah Data Excel

Video Comments to Video Likes Ratio memiliki karakteristik yang tinggi, artinya semakin tinggi nilai yang dihasilkan maka semakin baik kredibilitas dari performa akun tersebut. Untuk memberikan peringkat pada masing-masing Merek Smartphone, peneliti memberikan angka 5 kepada Merek yang mendapatkan nilai tertinggi dan angka 1 untuk Merek smartphone yang mendapatkan nilai terendah. Berikut merupakan tabel urutan nilai yang dihasilkan oleh masing-masing merek smartphone.

Tabel 8. Nilai Rasio Akun TikTok 5 Merek Smartphone Terlaris di Dunia

\begin{tabular}{|l|c|c|c|c|c|}
\hline \multirow{2}{*}{ Rasio } & \multicolumn{5}{|c|}{ Tabel Peringkat } \\
\cline { 2 - 6 } & Vivo_Indonesia & xiaomi.official & SAMSUNG & iphone_storess & OPPO \\
\hline $\begin{array}{l}\text { Video Comments } \\
\text { to Video Likes } \\
\text { Ratio }\end{array}$ & 1 & 3 & 5 & 4 & 2 \\
\hline
\end{tabular}

Sumber : Pengolah Data Excel

Dari Tabel Nilai Rasio Akun TikTok 5 Merek Smartphone Terlaris di Dunia dapat simpulkan bahwa Samsung mendapatkan nilai tertinggi untuk rasio Video Comments to Video Likes. Sedangkan akun TikTok Vivo Indonesia mendapatkan nilai terendah untuk rasio ini. Jadi, pada penelitian ini Samsung memiliki kredibilitas performa yang lebih baik dibandingkan dengan merek smartphone yang lainnya. 


\section{KESIMPULAN}

Tujuan dari penelitian ini adalah mengetahui kredibilitas performa dari akun TikTok 5 Merek Smartphone Terlaris di Dunia menggunakan Video Comments to Video Likes Ratio. Top 5 Merek Smartphone tersebut diantaranya : Oppo Indonesia, Samsung, Vivo Indonesia, Xiaomi Indonesia, dan Iphone Storess. Dari kelima merek smartphone tersebut dapat disimpulkan bahwa :

1. Peringkat pertama diraih oleh merek SAMSUNG dengan nilai tertinggi yaitu 0,07223554

2. Peringkat kedua diraih oleh merek iphone_storess dengan nilai 0,00399119

3. Peringkat ketiga diraih oleh merek xiaomi_official dengan nilai 0,01745051

4. Peringkat keempat diraih oleh merek OPPO dengan nilai 0,00399119

5. Peringkat kelima diraih oleh merek vivo_Indonesia dengan nilai terendah yaitu 0,00368513 


\section{DAFTAR PUSTAKA}

Adawiyah, Dwi Putri Robiatul. 2020. "Pengaruh Penggunaan Aplikasi TikTok Terhadap Kepercayaan Diri Remaja Di Kabupaten Sampang." Jurnal Komunikasi 14 (2): 135-48. https://doi.org/10.21107/ilkom.v14i2.7504.

Batam, Universitas Internasional. 2020. "ANALISIS FENOMENA SOSIAL MEDIA DAN KAUM MILENIAL : STUDI KASUS TIKTOK” 1: 565-72.

Gilar Ramdhani. n.d. "5 Merek Smartphone Terlaris Di Dunia."

Ishihara, Yemikaori Yumna Ulya, and Roswita Oktavianti. 2021. "Personal Branding Influencer Di Media Sosial TikTok.” Koneksi 5 (1): 76-82. https://doi.org/10.24912/KN.V5I1.10162.

Maryam, Siti, Isrok'atun Isrok'atun, and Ani Nur Aeni. 2016. "PENDEKATAN EKSPLORATIF UNTUK MENINGKATKAN KEMAMPUAN REPRESENTASI MATEMATIS DAN KEPERCAYAAN DIRI SISWA.” Jurnal Pena Ilmiah 1 (1): 55160. https://doi.org/10.23819/PI.V1I1.2984.

P3M STMIK Widya Cipta Dharma. n.d. “SEBATIK VOL 25 NO 1 - Google Books.” 2021.

Permana, I Putu Hendika, and Ni Putu Suci Meinarni. 2021. "Ratio Analysis on Tiktok (Social Media) for Qualitative Research Using Explorative Methods.” Jurnal Ekonomi \& Bisnis JAGADITHA 8 (1): 30-38. https://doi.org/10.22225/JJ.8.1.2944.30-38.

PRIANBODO, BAGUS. 2018. "PENGARUH 'TIKTOK' TERHADAP KREATIVITAS REMAJA SURABAYA," December.

Purnamasari, Nurjihan Pricillia, and Ririn Puspita Tutiasri. 2021. "Analisis Resepsi Remaja Perempuan Terhadap Gaya Hidup Berbelanja Fashion Melalui Tayangan Video 'Belanja Gak Aturan’ Dalam Akun Tiktok @ handmadeshoesby.” Jurnal Representamen 7 (01). https://doi.org/10.30996/REPRESENTAMEN.V7I01.5129.

Putri, Shani Dwi, and Suzy Azeharie. 2021. "Strategi Pengelolaan Komunikasi Dalam Membentuk Personal Branding Di Media Sosial Tiktok.” Koneksi 5 (2): 280-88. https://doi.org/10.24912/KN.V5I2.10300.

Rankuti, Freddy. 2015. "Buku Riset Pemasaran.” 2015.

“Top 5 Vendor Smartphone Di Indonesia Q1-2021 - Selular.ID.” n.d.

Wijaya, Mukhammad Handy dwi, and Musta'in Mashud. 2020. "Konsumsi Media Sosial Bagi Kalangan Pelajar: Studi Pada Hyperrealitas Tik Tok." Al-Mada: Jurnal Agama, Sosial, Dan Budaya 3 (2): 170-91. https://doi.org/10.31538/ALMADA.V3I2.734. 